\title{
DESENVOLVIMENTO ECONÔMICO TERRITORIAL E AS MACRODECISÕES: CASO DA LEI GERAL DA MICRO E PEQUENA EMPRESA NOS MUNICÍPIOS DE TAPES E CORONEL BARROS (RS)

\author{
ECONOMIC AND TERRITORIAL DEVELOPMENT AND MACRO
} \\ DECISIONS: GENERAL LAW MPE CASE IN TAPES AND CORONEL BARROS (RS)
}

\author{
Daniela Burkhard ${ }^{1}$ \\ Roger Pierre Vidal $^{2}$ \\ Jorge Moraes $^{3}$
}

\section{RESUMO}

A implementação da Lei Geral da Micro e Pequena Empresa (Lei $n^{\circ}$ 123/2006) é vista como uma importante ferramenta propulsora de desenvolvimento, pois desperta a vontade das empresas de sair da informalidade e ingressar no campo formal para poder participar ativamente dos processos de compras nas licitações públicas, processos estes antes vistos como oportunidade somente para grandes empresas. Nesse contexto, a Lei Geral é analisada como ferramenta de desenvolvimento regional e objeto de estudo deste trabalho. Para a realização do artigo utilizou-se pesquisa bibliográfica associada à investigação com foco teórico na pressão que a globalização gerou nos territórios, onde alguns perderam e outros ganharam, conforme Heidrich (2001). Cada vez mais as macrodecisões geram impactos nas regiões, como afirma Brandão (2004). A pesquisa evidenciou como resultado uma mudança considerável nos municípios de Tapes e Coronel Barros, quanto à distribuição de renda e à desburocratização na abertura de empresas.

Palavras-chave: Lei Geral. Desenvolvimento Econômico. Globalização.

\begin{abstract}
The implementation of the General Law MPE is seen as an important driving tool as it arouses people's willingness to leave the informal and formal joining the field to participate in procurement processes in procurement, once seen as opportunities only for large companies. The whole community, government and business owner is able to create networks of support and confidence that can be a solid foundation for the development. In this context, the general law is analyzed as regional and objects of study of this research tool. For its realization article we used the literature associated with research focus on theoretical pressure that globalization has generated in the territories, where some lost and others gained as Heidrich (2001). Increasingly macros decisions have impacts in areas as stated Brandão (2004), the research showed this effect results in a considerable change in the two counties analyzed in the study Tapes and Colonel Barros, who had considerable results in purchases and bureaucracy.
\end{abstract}

Keywords: General Law. Economic Development. Globalization.

\footnotetext{
${ }^{1}$ Faculdades Cenecista de Osório. Coordenadora do curso Gestão Comercial na Facos. Mestranda do Programa de Pós-Graduação em Desenvolvimento Regional (PPGDR) das Faculdades Integradas de Taquara - FACCAT - Rua 24 de Maio, 141, Centro Osório/RS. E-mail: dfxconsultoriampe@gmail.com

${ }^{2}$ Faculdades Integradas de Taquara. Mestrando do Programa de Pós-Graduação em Desenvolvimento Regional (PPGDR) das Faculdades Integradas de Taquara (FACCAT) - Av. Oscar Martins Rangel, 4500 - Fogão Gaúcho, Taquara, RS - CEP 95600-000. E-mail: rogerpvidal@ hotmail.com

${ }^{3}$ Faculdades Integradas de Taquara. Professor doutor do Programa de Pós-Graduação em Desenvolvimento Regional (PPGDR) das Faculdades Integradas de Taquara (FACCAT) - Av. Oscar Martins Rangel, 4500 - Fogão Gaúcho, Taquara, RS - CEP 95600-000. E-mail: jmoraes12@gmail.com
} 


\section{Introdução}

Esta pesquisa reveste-se da maior importância no âmbito da investigação em ciências sociais para o aprimoramento e a análise a ser empregadas como alavanca para o desenvolvimento regional. Com isso, o planejamento público, visando à integração de fatores de desenvolvimento, surge do reconhecimento da amplitude do fenômeno de implementação da Lei Geral das MPE, ${ }^{4}$ para o desenvolvimento de locais ou regiões com potencial adormecido, fundamentalmente relacionado aos aspectos interdisciplinares e convergentes da atividade.

A Lei Geral tem por objetivo fomentar o desenvolvimento coerente dos elementos físicos, econômicos, sociais, culturais, técnicos e ambientais, para empresários e poder público como nova ferramenta de desenvolvimento. Diante do que foi exposto, este trabalho visa investigar um conjunto de fatores relacionados à pressão da globalização e às tranformações nos territórios, por meio da análise presente nas relações de entidades e lideranças comunitárias nas regiãoes sul e noroeste do Rio Grande do Sul, analisando os reflexos proporcionados ao desenvolvimento do determinado espaço.

A referência são as cidades que tiveram a Lei Geral no 123/2006 (Lei de Desenvolvimento Econômico da Micro e Pequena Empresa) implementada, tendo o fator de desenvolvimento comprovado pode meio dessa nova fonte de circulação financeira, abertura de novos negócios e o ordenamento de Políticas Públicas de atendimento integrado no território para as compras governamentais, já que as MPE (Micro e Pequenas Empresas) representam 99,1\% (SEBRAE, 2012) do total de empresas do país. Isso se deve a enorme demanda de estudos que necessitam avançar na ótica do aprimoramento dos intercâmbios institucionais presentes nos setores público e privado.

A pesquisa foi estruturada em quatro partes. A primeira delas abordará a importância da implementação da Lei Geral n ${ }^{\circ}$ 123/2006 no processo de integração regional, com base nas regiões que já possuem larga tradição e sucesso comprovado, como a região sul e noroeste do Rio Grande do Sul. A segunda parte irá examinar as

\footnotetext{
${ }^{4}$ Lei Complementar no 123, a Lei das Micro e Pequenas Empresas - MPE - Micro e Pequenas Empresas.
} 
diversas possibilidades de inter-relação de negócios originados com o enquadramento de Empreendedor Individual, Microempresa e Pequena Empresa, mas em conexão com os demais setores da economia local, como os serviços públicos agregados e as compras governamentais realizadas. Na terceira parte, será apresentada a pressão da globalização nos territórios e os efeitos macros nas decisões na tranformação das regiões. Por fim, é feita a análise das ações integradas entre o setor público e privado, como condição básica para a criação de um ambiente favorável aos negócios, ou seja, a introdução da "Sala do Empreendedor". Nas conclusões finais, demonstra-se que a Lei Geral das MPE contribui para o desenvolvimento regional e, por extensão, para o fomento das ações para o desenvolvimento regional.

\section{A lei geral das micro e pequenas empresas e o desenvolvimento econômico}

Em âmbito nacional, desde 1984, quando foi promulgado o Primeiro Estatuto da Micro e Pequena Empresa, surgiu a necessidade de criar um ambiente legal que permitisse maior sobrevivência e desenvolvimento das MPE. A partir de então, foram iniciadas gradativas ações em favor das MPEs e em 2006 foi aprovada a Lei Complementar $\mathrm{n}^{\circ} 123$, a Lei das Micro e Pequenas Empresas.

O foco basilar da Lei Geral é criar um ambiente menos burocrático e com mais oportunidades para os pequenos negócios. Trata-se de uma lei que desonera e desburocratiza a abertura, o funcionamento e o fechamento de empresas. A Lei Geral Municipal não é uma lei tributária, mas que traz políticas públicas de Desenvolvimento Econômico para os municípios (SEBRAE, 2012).

No entanto, nossos municípios devem ser preparados para receber as informações de todas as melhorias dos procedimentos internos a ser incorporados pela administração pública, com a criação de uma figura denominada pela legislação como "Agente de Desenvolvimento", o qual terá o papel fundamental de integrar as informações público-privadas, como demonstrado na Figura 1, em escala de conceitos. 
Figura 1 - Agente de desenvolvimento

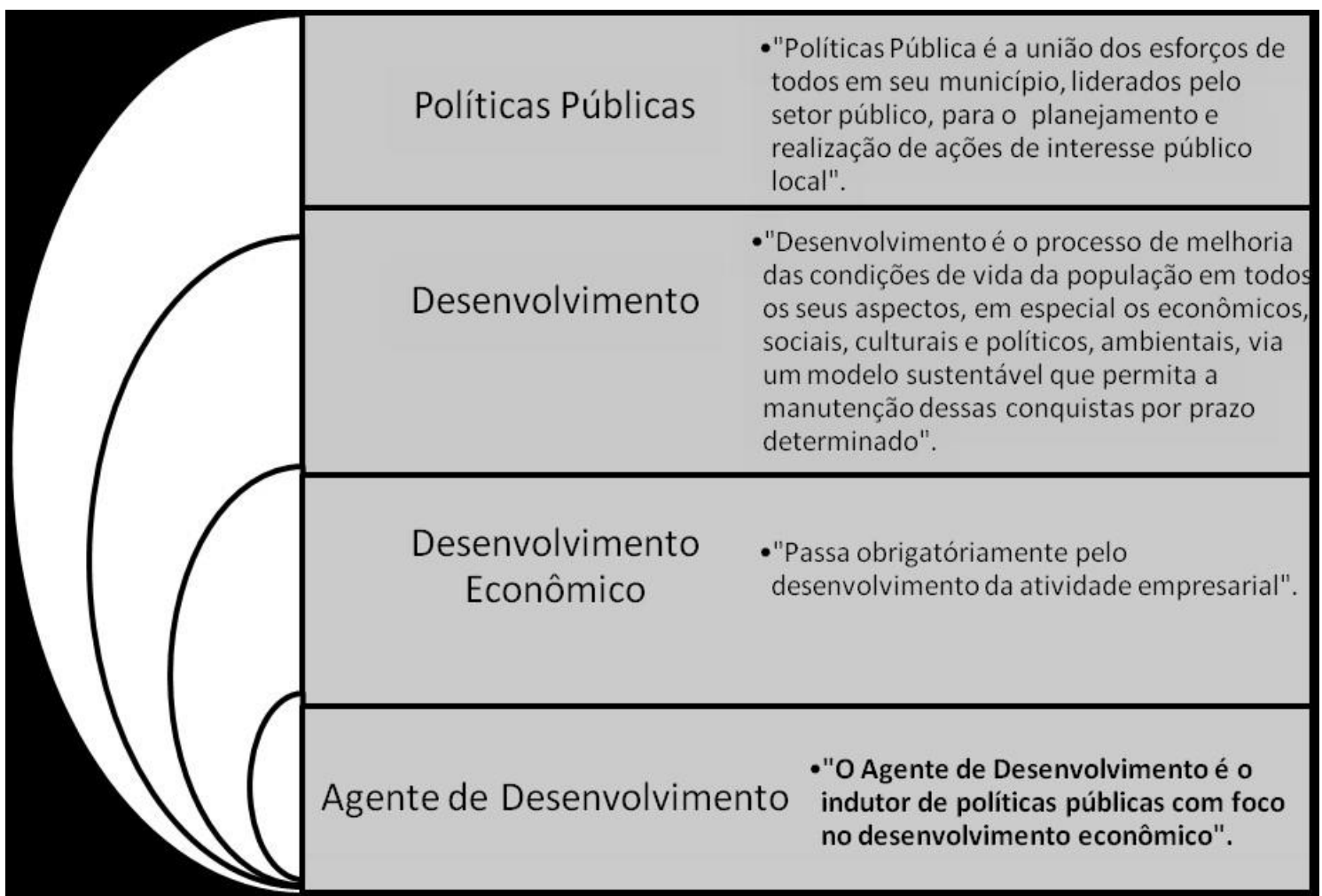

Fonte: SEBRAE - Curso de Formação de Agentes de Desenvolvimento (2009).

Nesse sentido fica evidente que não existe desenvolvimento sem a ação das empresas, as quais irão gerar a dinamização da economia com suas atividades comerciais. Já, para que sejam eficientes em alguns aspectos, as políticas públicas também devem cumprir o seu papel, gerando condições de desenvolvimento para as atividades empresariais na localidade onde as empresas estejam instaladas.

O Agente de Desenvolvimento poderá, dentro de suas atribuições, fazer o intercâmbio entre empresas e poder público, buscando, assim, auxiliar na formalização dos negócios e no diagnóstico das necessidades. Desse modo, ele poderá fazer com que as informações cheguem até as lideranças e se tenham novos mecanismos para o condicionamento das políticas públicas para novos negócios, como o acompanhamento da implementação dos artigos descritos na lei geral de seu município.

Esse cenário ocorre porque em uma organização social caracterizada por uma economia de mercado ou capitalista desenvolve-se um complexo tecido de relações diretas e indiretas pelas quais os homens chegam a dispor de uma variada gama de bens 
materiais, capaz de satisfazer suas múltiplas necessidades e desejos das mais diversas índoles. Assim, os homens dividem socialmente seu trabalho e atuam integrados mediante um intercâmbio de produtos e mútua prestação de serviços. As atividades produtivas de toda a organização social realizam-se através de unidades produtoras que, individualmente, articulam os fatores de produção, tradicionalmente conhecidos como natureza, capital e trabalho, em condições técnicas historicamente determinadas para a obtenção de bens e serviços. As unidades produtoras provocam o fenômeno da divisão social do trabalho.

As Micro e Pequenas Empresas representam mais de 99\% (SEBRAE, 2014) do total de empresas no país, portanto são elas que movimentam a economia local e distribuem renda. Nesse sentido, a Lei Geral cria condições para que esses negócios se fortaleçam e gerem mais emprego e dinamizem a economia, ampliando, assim, o ciclo de prosperidade dos municípios e os relacionamentos na cadeia empresarial e pública, o que é evidenciado nas condições de capital social que surgem (Putnam, 2006).

\subsection{Desenvolvimento através de suas dimensões escalares: a pressão da globalização nos territórios}

Em primeiro lugar, para pensar em desenvolvimento local, é preciso entender alguns fatores de contextualização sobre o assunto que podem ser importantes na atualidade, em que todos os pensamentos econômicos estão voltados para o território e sua divisão espacial. Então serão apresentadas as noções de espaço, território e territorialidade.

Espaço pode ter vários sentidos, mas, quando se trata da forma de desenvolvimento local, descreve a materialização geográfica dos processos e as atividades envolvidas na produção das condições de vida da sociedade. Para Santos (2006) é preciso reconhecer o espaço como um campo de relações, quando se trata de "coisas ou seres", que permanecem em determinado local e podem ser conferidos. O autor ainda completa que os espaços agregam a todos com múltiplas possibilidades e existem alternativas diferentes de uso do espaço. 
Observando o conceito expresso por Milton Santos (1997, apud SUERTEGARAY, 2001, p. 2):

O espaço geográfico constitui "um sistema de objetos e um sistema de ações" que: é formado por um conjunto indissociável, solidário e também contraditório, de sistemas de objetos e sistemas de ações, não considerados isoladamente, mas como um quadro único na qual a história se dá. No começo era a natureza selvagem, formada por objetos naturais, que ao longo da história vão sendo substituídos por objetos fabricados, objetos técnicos, mecanizados e, depois, cibernéticos, fazendo com que a natureza artificial tenda a funcionar como uma máquina.

O mesmo autor confirma o espaço como uma criação dos indivíduos por meio de suas próprias ações. Nesse contexto os espaços são criados e se desenvolvem através do tempo de interação entre indivíduo e natureza e também na influência mútua entre as próprias pessoas ao longo da história.

Dessa forma o espaço comparece no estudo da dimensão espacial do desenvolvimento, e é entendido como a palavra que aponta e descreve a materialização geográfica dos processos e atividades envolvidos na produção e reprodução das condições de vida da sociedade. Então, o espaço para uma análise sobre a ótica do desenvolvimento local pode ser definido como a vida em sociedade e espelha aspectos centrais do funcionamento dela.

Lins (2009) mostra que o espaço tem uma forma muito complexa na atualidade:

Uma sociedade capitalista moderna, que apresenta uma enorme gama e complexidade de fluxos e de "cristalizações" geográficas - fábricas, infraestrutura etc. -, exibe formas espaciais igualmente complexas, multiestratificadas ao nível das atividades econômicas, das áreas urbanas e suas superfícies de abrangência e das interligações multiescalares (escalas regionais, nacionais, internacionais) que as envolvem. (LINS, 2009, p. 12)

O espaço no desenvolvimento vincula-se á ideia de que ao produzir as formas para a sua sobrevivência os indivíduos, por meio de interações, criam objetos, como áreas de plantio, fábricas, estradas, portos etc., que se distribuem na superfície terrestre. Essa ação implica a transformação da natureza selvagem, resultando no surgimento de uma natureza artificial. Quando é produzida a natureza artificial, cria-se uma relação 
social, e o resultado dessa relação, segundo Lins (2009), é a organização espacial da sociedade, ou seja, o espaço - além de espelhar a sociedade e ser resultado de seu funcionamento e de traduzir as relações sociais - é também determinante dessa mesma relação.

Com o desenvolvimento das relações sociais surgem as territorialidades, pois, por meio da organização espacial, os atores sociais em determinado espaço geográfico alinham-se a um sentimento de sobrevivência do todo, mesmo com a diversidade dos interesses ali presentes. Conforme Heidrich (2004), o território nasce das relações dos indivíduos com o espaço, sendo que a organização espacial está ligada ao sentimento de territorialidade. Nesse sentido, há uma ligação indissociável entre espaço e território no desenvolvimento local, pois, segundo o autor, ter consciência de espaço refere-se a um sentimento de pertencer a um território. Trata-se de criar identidade e relacionar-se com os interesses de determinado espaço, o que vai criar os territórios, já que, para Heidrich (2004), a territorialidade cria o território.

Brandão (2004) afirma que o território é a construção social conflituosa, construído através da interação dos agentes locais, numa intensa relação de poder. Então, quando se fala em desenvolvimento local, o território não pode ser confundido com um sítio fixado. O território nasce das relações sociais em cada localização geográfica, onde os agentes sociais fixam-se e constroem escalas de cooperação e competição.

\subsubsection{Integração nacional e o processo da globalização}

Quando a organização espacial tem seu completo desenvolvimento das relações sociais se estabelece a condição territorial. E é nesse momento que passa a existir a manifestação generalizada de um poder, pelo qual, segundo Heidrich (2004), cria-se o território estatal-nacional que é o que mais visivelmente reúne todo esse desenvolvimento.

No Estado moderno, com o desenvolvimento das relações sociais, surge o território nacional, o que consiste em distinguir as sociedades umas das outras. Essa distinção também vai acontecer internamente no território. De acordo com Heidrich (2004), criam-se configurações diferenciadas espacialmente, sendo o Estado 
responsável por construir o coletivo, permitindo que cada indivíduo identifique-se com ele. Desse modo, os interesses das regiões são frutos das relações de poder. Os espaços regionais estão ligados aos interesses de um espaço maior. Brandão (2004) sintetiza melhor essas articulações para o desenvolvimento regional:

Cada problema tem a sua escala espacial específica. É preciso enfrentá-lo a partir da articulação dos níveis de governo e das esferas de poder pertinentes àquela problemática específica. Além das articulações intrarregionais é importante ampliar seu raio político de manobra a fim de negociar sua inserção inter-regional. Explicitar os conflitos de interessem cada escala e construir coletivamente a contratualização das políticas públicas. Tratar de forma criativa escalas, níveis e esferas, lançando mão de variados instrumentos, politizando as relações, construindo cidadania e buscando combater as coalizões conservadoras. (BRANDÃO, 2004, p. 61)

O território tem diferentes níveis de análise, mas para entende-lo nacionalmente e seus conjuntos espaciais, é preciso compreender o conjunto e suas articulações como um todo e em todas as esferas dos conjuntos, para assim apreender o desenvolvimento local. Não é possível entender o desenvolvimento local apenas em seu conjunto espacial local, pois o desenvolvimento é feito por meio da articulação nos diferentes níveis escalares.

A globalização ${ }^{5}$ foi um processo que reestruturou o mercado mundial através das novas tecnologias, em que tudo e todos estão integrados. Essa conexão materializou-se de forma desigual no decorrer das últimas décadas, provocando um aumento maior dos diferenciais inter-regionais, salientando uma profunda desigualdade. A globalização quebrou o sistema de integração até então existente, em que a cooperação econômica local e nacional perdeu força para uma integração global, sendo que as regiões mundiais mais fortes economicamente saíram na frente. As regiões que antes eram prósperas foram condenadas à pobreza, através da pressão pela integração total, conforme descreve Heidrich (2004):

Este processo tem efeito direto para o próprio sistema, pois o aumento da concorrência intercapitalista também faz concorrer entre si os sistemas nacionais e regionais de normatizações. Funciona como "pressão" para a unificação, para que as relações comerciais ocorram com as mesmas regras. [...]. Desta forma, a globalização, vista como a

\footnotetext{
${ }^{5} \mathrm{~A}$ globalização é um dos processos de aprofundamento internacional da integração econômica, social, cultural, política, que teria sido impulsionado pelo barateamento dos meios de transporte e comunicação dos países no final do século XX e início do século XXI.
} 
etapa atual de um processo maior de continua integração em âmbito mundial, interfere também nas demais escalas das integrações sócias espaciais, como o cotidiano de comunidades locais, sociedades regionais e nacionais. (p. 47)

A globalização tornou-se uma forma de pressão para unificação, afetando inevitavelmente o funcionamento dos Estados Nacionais e a viabilidade do sistema de integração local. Tomazzoni (2008) afirma que, na nova dimensão de território das cadeias globais atual, a noção de território transcende o aspecto geográfico e abrange pontos distantes, ligados por formas e processos sociais. Esse espaço econômico é organizado hierarquicamente com seu comando concentrado em cidades mundiais, nas quais a tecnologia da informação tem papel relevante. As palavras de Heidrich (2004) exemplificam bem o que ocorreu com a globalização, isto é, houve uma ruptura da solidariedade local construída no Estado moderno, em que as novas tecnologias substituem a continuidade física pelo tempo compartilhado no espaço de fluxos.

\section{Metodologia da pesquisa}

Este estudo adotou como procedimento metodológico métodos e técnicas de pesquisa. Quanto ao método, dedutivo de investigação, buscou-se o conhecimento dos fatos a partir da generalização para a aplicação no particular, que está em consonância com a natureza dos trabalhos a serem desenvolvidos neste estudo. Também se caracteriza como um estudo exploratório nos setores público e privado, e sua ligação com o desenvolvimento econômico através da Lei Geral. Para Gil (2006, p. 78), “a pesquisa exploratória de natureza experimental procura analisar o problema manipulando os possíveis fatores, as variáveis, os que se referem ao fenômeno observado de acordo com as hipóteses levantadas".

As técnicas utilizadas foram de investigação com a documentação indireta, através da leitura em obras clássicas sobre o assunto, bem como em periódicos e artigos. Existem muitas maneiras de se fazer pesquisas nas ciências sociais, como experimentos, levantamentos, pesquisas históricas, pesquisas de avaliação, observação participante, entre outras. Para este estudo, pesquisou-se inicialmente as experiências bem-sucedidas em implementação da Lei Geral das MPE, selecionando as variáveis para fins de confrontação com outras realidades. Num plano final, foram examinadas, à luz do 
levantamento empírico das experiências selecionadas, as conclusões propostas nos objetivos deste trabalho, a fim de subsidiar estudos do tema em questão.

\section{Análise dos dados}

Esta pesquisa tem grande importância no âmbito da investigação em ciências sociais para o aprimoramento e a análise a ser empregada como alavanca para o desenvolvimento regional.

Com isso, o planejamento público, visando à integração de fatores de desenvolvimento, surge do reconhecimento da amplitude do fenômeno de implementação da Lei Geral das MPE, para o desenvolvimento de locais ou regiões com potencial adormecido, fundamentalmente relacionado aos aspectos interdisciplinares e convergentes da atividade. O objetivo aqui foi o desenvolvimento coerente dos elementos físicos, econômicos, sociais, culturais, técnicos e ambientais, para empresários e poder público, com essa nova ferramenta de desenvolvimento.

A pesquisa e o consequente planejamento das ações de desburocratização para abertura de novos negócios supõem o maior aproveitamento dos recursos potenciais evitando que um plano produza um aproveitamento deficiente das possibilidades da região vocacionada para o processo de formalização dos negócios enquadrados como MPE. Assim, a estrutura do sistema é constituída pelos elementos e suas relações, expressando-se através do arranjo de seus componentes. Por exemplo, é possível realizar o planejamento das ações a ser realizadas por um grupo de pessoas com aproveitamento das forças e oportunidades identificadas para o município, ou seja, todos os aspectos positivos que o município possui ou pode vir a possuir com os benefícios gerados pela implementação da Lei Geral no 123/2006. Além disso, pode-se aproveitar a capacidade empreendedora das empresas locais fomentando o comércio local por meio de compras governamentais feitas pela prefeitura.

Os resultados ficam mais expressivos na medida em que analisamos municípios com Lei Geral já implementada, ou seja, com políticas de desenvolvimento econômico local das MPEs em funcionamento. Como objeto de estudo, buscou-se saber o impacto na economia local dos benefícios aplicados às MPE para abertura e formalização dos negócios. 
No caso de Tapes, na região sul do Rio Grande do Sul, a lei geral aprovada em 2009 realizou diversas modificações nos procedimentos de abertura das empresas, com a nomeação do agente de desenvolvimento, criação do espaço do empreendedor, consulta prévia orientada, reenquadramentos para empresas, regularidade fiscal, dentre outras, como capacitações via convênios como o SEBRAE-RS.

O resultado é eminente. Foram gerados $507^{6}$ novos empreendimentos enquadrados como Microempreendedores Individuais. Com eles - a grande maioria ainda ativa -, vieram mais arrecadações ao poder público local, o qual, com receita nova, pode fazer melhorias na cidade de pouco mais de 16 mil habitantes. $\mathrm{Na}$ arrecadação municipal, foram incorporadas as seguintes receitas advindas desse novo público arrecadatório (MEI) antes não existentes:

- ISS - Imposto sobre Serviços;

- Taxa de Renovação de Alvarás,

Durante a pesquisa, foi possível analisar que chegaram por ano, desde 2009, aproximadamente R\$ 37 mil de receitas advindas das contribuições dos Microempreendedores formalizados em Tapes, dados estes da Sala do Empreendedor, em 9 de setembro de 2013.

Foram verificados alguns serviços prestados pela Sala do Empreendedor de Tapes que resultaram em um relacionamento de negócios entre poder público e empresários, que são a Consulta Prévia de Localização, formalização de empresas, emissão de alvarás, regularidade fiscal, alteração de empresas para ME, EPP, ou o inverso, e para EIRELI, cursos de capacitação em parceria como SEBRAE-RS, divulgação de planejamento de compras e parcerias com o Copo de Bombeiros para inspeção e alvarás das empresas.

Outro município estudado foi o de Coronel Barros, a noroeste do Rio Grande do Sul, com aproximadamente 2.500 habitantes, no qual a implementação da Lei Geral gerou benefícios para as empresas por meio das compras públicas, em que foram analisados os editais exclusivos às MPE (art. 48, parágrafo I, da Lei Geral nº 123/2006,

\footnotetext{
${ }^{6}$ Fonte: Sala Empreendedor de Tapes/RS, 31-08-2013.
} 
versa sobre licitações exclusivas de até $\mathrm{R} \$ 80$ mil), e trouxe distribuição de renda pela descentralização do fornecimento de produtos. O resultado é expressivo, pois a redução de valores nas compras para a Prefeitura Municipal, ou seja, a economicidade, chegou a $35 \%$ em apenas uma licitação realizada para compra de produtos de informática, no primeiro semestre de 2013, período analisado nesta pesquisa.

\section{Considerações finais}

O espaço no desenvolvimento vincula-se à ideia de que, ao produzir as formas para sua sobrevivência, os indivíduos por meio das interações criam objetos. Essa ação implica a transformação da natureza selvagem, resultando no surgimento de uma natureza artificial. Quando é produzida a natureza artificial, cria-se uma relação social, cujo resultado, segundo Lins (2009), é a organização espacial da sociedade. Afirma-se também que o espaço, além de espelhar a sociedade e ser resultado de seu funcionamento e traduzir as relações sociais, é também determinante dessa mesma relação.

O aumento do capitalismo pressupõe a aplicação da concorrência, onde cada vez mais as pequenas empresas são pressionadas pelas empresas internacionais. Neste cenário, também surge uma pressão entre os sistemas nacionais e regionais como uma forma de unificação, para que as relações comerciais ocorram com as mesmas regras. Desta forma, a globalização, vista como a etapa atual de um processo maior de continua integração em âmbito mundial, interfere também nas demais escalas das integrações sócias espaciais, como o cotidiano de comunidades locais, sociedades regionais e nacionais (Heidrich, 2004, p. 47). A globalização "quebrou" o sistema de integração até então existente, em que a cooperação econômica local e nacional perdeu força. Nesse sentido, as macrodecisões, como as tomadas na aplicação da Lei Geral da Micro e Pequena Empresa, apresentam-se como forma de proteger e criar condições para o desenvolvimento local, por meio de ambientes favoráveis à geração de novos negócios e novas formas de incentivos criadas pela legislação. Cabe aos municípios ampliar seu raio político de forma a inserir o local nas articulações políticas de esferas superiores. As administrações públicas locais devem construir coletivamente as políticas públicas, construindo cidadania e buscando combater as coalizões conservadoras. 
A pesquisa constatou que desenvolvimento econômico local passa pelas macrodecisões adotadas pelo governo federal, o qual cria benefícios que serão aplicados no âmbito da federação. Como um bom exemplo, a decisão política de regulamentação e posterior aplicação da Lei Geral das MPE pelos municípios, que mantêm os recursos financeiros girando na economia regional, gera investimentos públicos e privados, promove a inclusão de pessoas que antes estavam em situação irregular e aproxima as redeS de relacionamentos entre poder público e privado, criando, assim, um ambiente favorável aos negócios e à geração de riquezas.

O trabalho mostrou que as macrodecisões como a Lei Geral das MPE tiveram resultados positivos nos casos dos municípios do Rio Grande do Sul, Tapes e Coronel Barros, que articularam suas políticas em consonância com as esferas escalares superiores. Os efeitos em Tapes, como já citado no corpo do trabalho, foram a geração de 507 novos empreendimentos enquadrados como Microempreendedores Individuais. Esses novos empreendimentos contribuíram para aumentar a arrecadação do município, da União e do Estado, cujo valor pago mensalmente agrega os tributos das três esferas em uma guia única. Em Coronel Barros, a implementação da Lei Geral trouxe benefícios às empresas através das compras públicas, tendo como resultado uma melhor distribuição de renda, já que as empresas participantes passaram a ser a região onde ocorreu a descentralização de fornecimento de produtos, com efeito expressivo ocorreu a redução de valores nas compras para o Municipal, ou seja, a economicidade do órgão comprador.

Conclui-se que é possível demonstrar, através das pesquisas nos municípios brasileiros, como as instituições públicas podem gerenciar as políticas para o desenvolvimento econômico através da implementação da Lei Geral das Micro e Pequenas Empresas nos territórios e assim criar condições de aproximação das lideranças e organizações para uma gestão pública eficiente e estratégica com os recursos advindos da Lei Geral. Apenas com o entendimento dessa lei e com a aplicação dos capítulos pertinentes, conforme as potencialidades de cada região/local, pode-se minimizar os impactos da globalização nos territórios nos quais todos tendem a ser impactados de acordo com o que foi apresentado por Santos (2006). 


\section{REFERÊNCIAS}

BANDEIRA, P. Participação, articulação de atores sociais e desenvolvimento regional. In: BECKER, D. F.; BANDEIRA, P. (Org.). Determinantes e desafios contemporâneos. Santa Cruz do Sul: EDUNISC, 2000.

BERNARDO, M. S. Distritos Industriais - Clusters. FEA/USP-RP, 1999 (Texto para discussão $\left.n^{0} 3\right)$.

BRANDÃO, C. A. Revista Paranaense de Desenvolvimento, n. 107, p. 57-76, jul./dez. 2004.

CASTELLS, M. A sociedade em rede. Trad. Ronei de Venâncio Majer. São Paulo: Paz e Terra, 1999.

GIL, A. C. Como elaborar projetos de pesquisa. 3. ed. São Paulo: Atlas, 2006.

HEIDRICH, A. L. Território, Integração sócio espacial, região, fragmentação e exclusão social. In: RIBAS, A. D.; SPOSITO, E. S.; SAQUET, M. A. (Orgs.). Território e Desenvolvimento: diferentes abordagens. Francisco Beltrão: UNIOESTE, 2004. p. $37-66$.

LINS, H. N. Economia regional e urbana. Florianópolis: Departamento de Ciências UFSC: 2009.

Florianópolis, cluster turístico? Revista Turismo em análise, v. 11, n. 2, p. 5570, nov. 2001.

Interações, aprendizagem e desenvolvimento: Ensaio sobre o turismo em Florianópolis. Revista Turismo - Visão e Ação, Florianópolis, v. 9, n. 1, p. 107-120, jan.-abr. 2007.

OBSERVATÓRIO DA LEI GERAL DA MICRO E PEQUENA EMPRESA. Disponível em: <http://www.leigeral.com.br/>. Acesso em: 10 ago. 2013.

PORTAL DO DESENVOLVIMENTO. Disponível em: <http://www.portaldodesenvolvimento.org.br/>. Acesso em: 9 ago. 2013. 
PORTAL

DO

EMPREENDEDOR.

Disponível

em:

<http://www.portaldoempreendedor.gov.br/sobre-portal/tipos-de-empresa>. Acesso em: 8 ago. 2013.

PUTNAM, R. D. Comunidade e democracia: a experiência da Itália moderna. Rio de Janeiro: FGV, 1996.

RIEDL, M. Associativismo e desenvolvimento: considerações sobre a existência de capital social. In: Capital social e desenvolvimento regional. Santa Cruz do Sul: EDUNISC, 2003.

SANTOS, M. O Brasil: território e sociedade no início do século XXI. Rio de Janeiro: Record, 2001.

SEBRAE - RS. Manual de implementação da Lei Geral, passo a passo de implementação e evidências para cada capítulo. 2013.

SEBRAE. Desenvolvimento Econômico Territorial - DET - Estratégias de atuação do - módulo 3. 2012.

TOMAZZONI, E. L. Turismo e desenvolvimento regional: dimensões, elementos e indicadores. Caxias do Sul: EDUCS, 2009. 219p.

VERAS, C.; BARCELlOS, F.; OLIVEIRA, I.; SOUZA, C. Curso de formação de agentes de desenvolvimento. Brasília: FNP; SEBRAE NA, 2009.

Recebimento dos originais: 20/04/2014

Aceitação para publicação: 15/06/2014 